\title{
Critical Professional Discourses About Information and Communications Technologies and Social Life in the U.S.
}

\author{
Rob Kling \\ SLIS, Indiana University at Bloomington \\ kling@indiana.edu
}

Abstract: Looking back over the 1990s, it is also easy to see the widespread troubles of many ventures that depended upon advanced IT applications, including business process reengineering projects, enterprise systems, knowledge management projects, distance education courses, and famously -- some of the dot-com businesses of the 1990s. These "troubles" vary from substantial underperformance (ie. projects that were much more costly and/or produced much less social or business value than most of the participating IT professionals anticipated) and many outright failures. Many of these 'troubles" could have been avoided (or at least ameliorized) if the participating IT professionals had much more reliable and critical understanding of the relationships between IT configurations, socio-technical interventions, social behavior of other participants in different roles, and the dynamics of organizational and social change. Social Informatics is the name for the field that studies and theorizes this topic, and I will discuss it in more detail below. The key issue addressed in this paper is who will produce social informatics research for IT professionals, and where will they learn about important findings, theories, design approaches, etc.? The paper examines the record of computer science in the U.S. as a major contributor to the relevant research and teaching. It also examines the possibilities for new kinds of academic programs -- sometimes called "information schools" and "IT Schools" -- that are being developed to expand beyond the self-imposed boundaries of computer science and to integrate some organizational and social research as sites for social informatics.

Key words: computer science education, social informatics, organizational informatics, information science, IT professionals, cultural models, IT discourses

The original version of this chapter was revised: The copyright line was incorrect. This has been corrected. The Erratum to this chapter is available at DOI: 10.1007/978-0-387-35609-9_29 


\section{INTRODUCTION}

In the 1990s, I argued that IT professionals (and especially computer science students) were being inadequately educated for the roles they were often playing in conceiving, developing and supporting new applications of information and communications technologies (IT) [22][23]. In particular, they were not learning empirically anchored analytical approaches to understanding the relationships between IT applications and human life in organizations and the larger society. I don't believe that my argument was particularly influential.

This article is more likely to be better appreciated in 2002 than its precursors were in the early 1990s. First, the cultural history of IT applications in the U.S. has changed substantially in the last decade. This recent cultural history include both the widely experienced benefits of public access to the Internet including the rise of new popular online services (such as e-Bay and Napster), and the demise of many dot-coms whose constitution as businesses was poorly understood. In addition, there are emerging new educational formations beyond computer science -- sometimes call Information Schools or IT Schools -- for educating IT professionals. This paper will examine whether these new educational programs provide more promising opportunities for educating IT professionals who can be more competent in developing workable and socially beneficial IT applications. In addition, this paper benefits from new lines of theorizing and new kinds of IT research from the late 1990s.

Looking back over the 1990s, it is also easy to see the widespread troubles of many ventures that depended upon advanced IT applications, including business process reengineering projects, enterprise systems, knowledge management projects, distance education courses, and famously - some of the dot-com businesses of the 1990s. These "troubles" vary from substantial underperformance (ie. projects that were much more costly and/or produced much less social or business value than most of the participating IT professionals anticipated) and many outright failures. It is difficult to find reliable estimates of the magnitude of these problems. It is often repeated that $70 \%$ of reengineering projects failed. However, some that "succeeded" also lead to firing thousands of employees in ways that cost organizations important expertise and subsequent business. In the case of the dot-coms, some estimate that their failure several billion dollars were drained from the U.S. stock market. In the case of distance education, it is difficult to quantify the distress of some students during their classes and their relative learning [14].

I suspect that many of these 'troubles" could have been avoided (or at least ameliorized) if the participating IT professionals had much more 
reliable and critical understanding of the relationships between IT configurations, socio-technical interventions, social behavior of other participants in different roles, and the dynamics of organizational and social change. It would be foolish to hold IT professionals solely responsible for the troubles, since other managers and professionals also played key roles in devising these projects. Social Informatics [24] is the name for the field that studies and theorizes this topic, and I will discuss it in more detail below (also see http://www.slis.indiana.edu/SI).

The key issue addressed in this paper is who will produce social informatics research for IT professionals, and where will they learn about important findings, theories, design approaches, etc.? In particular, I will examine the record of computer science in the U.S. as a major contributor to the relevant research and teaching. I will also examine the possibilities for new kinds of academic programs -- sometimes called "information schools" and "IT Schools" -- that are being developed to expand beyond the selfimposed boundaries of computer science and to integrate some organizational and social research as sites for social informatics.

\subsection{What can we learn from bridge designers?}

The contrast between IT projects and the design of long span suspension bridges, such as the Golden Gate Bridge, is instructive. Petroski [44] examines how the craft of engineering these bridges developed in the 19th century, when new British bridges periodically failed during their construction or use (by trains). He describes how John Roebling, designer of the Brooklyn Bridge, paid intense attention to the failure modes of previous bridges to develop both a design and construction practices that would be safe and robust.

Roebling's engineering was critical in the sense that he carefully analyzed different designs, and their strengths and weaknesses. The term "critical" has several meanings, but all too many IT professionals identify it with faultfinding. Roebling loved bridges, and his critical analysis enabled him to design a bridge that was completed in 1883 and that is still functioning well today. Petroski notes that bridge designers learned much more from bridge failures than from what seemed like bridge successes. He also notes that over periods of 30 or more years, the design ideas that were carefully developed in one design paradigm seem to be forgotten, and newer bridges risk from suffering the failure modes of much older bridges. The abstract design issues for bridges have not changed much over time: to reliably carry people from one place to another, with certain vehicles, with certain aesthetics, and within specific construction and maintenance cost constraints. In contrast, 
the abstract design issues for new IT applications can change dramatically every decade.

Roebling was aided by the ways in which long span bridges are public structures. Their designs are visible, their collapses are very notable and discussions about them are available for retrospective review. In contrast, many IT projects are relatively private, and "their troubles" are much harder to learn about analytically and systematically. Further, their effective sociotechnical design is much more complex than that of bridges. After all, specific IT applications may work technologically, but not be utilized by the people who are supposed to benefit from them or used in ways that seem "counter-productive."

\subsection{Reliable Knowledge about IT and Social Life for IT Professionals}

Without ethnographic research about the troubles of some large scale expert systems [34], knowledge management projects [43], distance education courses [14], and on-line professional development forums [26], we would not have the quality of accounts to help us better conceptualize their failure modes. Unfortunately, the ideas from studies like these, or more integrated analyses that are based upon them [47], are rarely part of the educations of IT professionals.

There are, of course, exceptions to this grim claim. In the field of software engineering, there have been important analyses of the failure modes of large scale software development projects [5], as well as illustrative examples [40], and integrated analytical guidebooks [32]. In the U.S., some computer science students can take a course that examines IT applications and social life in a critical perspective [23][19]. Some students in information systems may be exposed to critical analyses of IT and organizational life [47]. However, these courses that examine IT and social life with a critical orientation constitute a tiny fraction of the formal education of IT professionals. Further, given the numerous families of IT applications and the varied contexts of their use, there is actually a relative paucity of reliable socio-technical research that is accessible to students in IT programs or to working IT professionals that is developed in ways that its contemporary relevance clear.

One key irony of information societies is that much of the discussion about them characterizes them as dependent, in part, upon advanced IT applications. However, the majority of IT professionals who develop these applications often seem ill educated to understand and anticipate their likely failure modes. I am making this sweeping claim based upon over 30 years of research, consulting and teaching in computer science, information science 
and information systems. However, this is an empirical claim that could be investigated more systematically.

The focus of this paper is on the production of reliable socio-technical knowledge that could inform professional IT practice. Who in the U.S. will produce the critical professional knowledge to help IT professionals reliably answer questions such as the following?

* Under what conditions will providing Internet access to K-12 schools actually improve children's education? [45]

* What kinds of "digital government" services and activities are likely to improve the actual responsiveness and transparency of local, state and federal government agencies? [12]

* What kinds of IT applications and organizational changes may improve the abilities of professionals in an organization with multiple offices to share their expertise? [43]

* Under what conditions can public access to the Internet improve the quality of political discussion and strengthen the vitality of civil society?

This paper raises this question, and examines some possible answers -academic computer science department and the emerging "information schools" and "IT schools."

\section{DISCOURSES, CULTURAL MODELS AND THEIR INSTITUTIONAL CIRCUITS}

First, I will develop three key concepts: discourses, cultural models and institutional circuits.

\subsection{Discourses}

Linguists characterize discourse as "language in use, or more broadly, the interactive production of meaning [2]." Socio-linguist James Gee [13] characterizes discourse in a less linguistic, and more cultural manner to refer to what is often communicated about certain topics within the constraints of a given time, place, or organizational, cultural, or institutional setting. Thus we could contrast "the discourse of computer scientists about the ARPANET in the early 1980s," "the official discourse about public access to the Internet by the Clinton/Gore administration in the mid-1990s," "the mid-1990's 
discourse about how the Internet can expand the range of scholarly communication," and "the current discourse about strategic marketing on the Internet." Further, Gee treats discourse as including symbols, places and social practices. Thus, today, someone who advances a position about ubiquitous computing and is carrying a cute PDA that is organized for wireless email, engages in a discourse with highly evocative symbols as well as conventional language.

Gee makes a distinction between "Big D" and little "d" discourses. Little "d" discourses are "language-in- use" like conversations. "Big D" Discourses are language plus "other stuff". Gee [13] characterizes "big D" Discourses as "socially accepted associations among ways of using language, of thinking, valuing, acting, and interacting in the 'right' places and at the 'right' times with the "right' objects." In my view, little "d" discourses are often local to some group or organization, while big "D" discourse -- like the examples above -- are much more societal in scale.

Discourses are not homogeneous. They can include debates, but they are circumscribed by the terms in which the debates and differences are structured. Further, even little 'd" discourses can be contradictory. Walsham [47] found that the discourses about using groupware in certain organizations -- especially Lotus Notes databases -- was often contradictory. Some of his informants characterized their Notes applications as empowering low level staff in a large organization, while others characterized these same applications as controlling by enabling high level managers to more closely observe the behavior and discussions of their subordinates who were working in other places.

Both big "D" and little "d" discourses can change over time. My opening examples point to the ways that Discourses about the social character of transorganizational and public access computer networking has changed since the early 1980s, and how different Discourses can be institutionally situated. Heracleous and Barrett[16] examine several major shifts in the little "d" discourses about a computerized trading system (EPS) used in the London Insurance Market by underwriters of Lloyds. EPS did not change much during their observations between 1990 and 1998. But the terms of the arguments about whether EPS should automate risk placement among underwriters or simply record insurance transactions that were placed through traditional verbal presentations changed substantially several times between 1990 and 1998. 


\subsection{Cultural Models}

Discourses are enacted through language, symbols and practices that have to be intelligible to many participants who have varied local experiences. They depend, in part, upon what cognitive anthropologists refer to as "cultural models." A "cultural model of X" refers to conventional conceptions of about $X$ within a group. In cognitive psychology and artificial intelligence these are sometimes called schemas, but their cultural variation is usually unexamined.

A simple example of a cultural model could be a "chicken dinner." A standard North American "chicken dinner" would be formed around a plate which contains a large piece of chicken (such as a breast or thigh), some vegetables, and a wheat-based bread. This "main dish" could be preceded by courses that include a salad or soup, and could be followed by a large desert. In contrast, standard Chinese "chicken dinner" would be formed around one or more dishes in which the chicken is finely chopped and mixed in with various vegetables. It would be accompanied by rice, which is served in a separate bowl. A course of soup might precede the main course, and it might be followed with a very small desert. These cultural models are well known to participants respectively in North American and Chinese cultures, as well as to people who have eaten the foods of the "other cultures." Cultural models set expectations and enable routine behavior. Of course, their can be culture clash, as when a Hungarian friend of mine tried to order bread when he first visited a Chinese restaurant and was outraged that they did not serve bread.

Sometimes cultural models have different underlying practices, but the similarity of terms masks important differences. "Peer reviewed articles" are an important form of scientific communication in North American research universities. However, the standards for peer review vary across fields (as well as across journals and conferences within a field). It is common for top rated Computer Science journals to accept less than 50\% of the submitted papers; reviews are conducted by two to four reviewers. In contrast, the prestigious Astrophysical Journal accepts over $80 \%$ of the submitted articles; articles are reviewed by one reviewer, and authors may request a different reviewer if they dislike the review of their article. University committees that review academic appointments and promotions may often count the number of "peer reviewed articles" for an astrophysicist and a computer scientist as if they are identical, while in practice the computer science review process may be much more stringent.

While cultural models enable social life by conventionalizing our expectations, they can also be misleading and even damaging when they radically oversimplify complex realities. A simple example is the American 
cultural model of romance that was based on Ms. Right finding Mr. Right and "falling in love" at first sight, and living "happily ever after." While fewer people may hope to enact this cultural model now than in the 1950's, the extent to which some people characterize themselves as "incurable romantics" to potential marital partners suggests that it is still a serious dream for many.

More seriously for us are the cultural models of IT applications and services that are parts of certain Discourses. For example, the Discourse about electronic journals (e-journals) seems to be specially confused today. The 1990s has been the era of the practical rise of e-journals. However, the dominant form of e-journals changed three times in the 1990s, and some of the research was not sufficiently sensitive to these rapid and important shifts. In the early 1990s, "pure e-journals" that were circulated by mailing lists were dominant. In the mid-1990s, pure e-journals that were stored on searchable gopher and WWW sites were dominant. These journals were usually free to authors (no page charges), free to readers, and had limited circulation of a paper edition, if any.

By 1996, several large commercial publishers created electronic editions of some of their paper journals. By 1998, these new dual paper-electronic (pe) editions numbered in the thousands and were by far the most numerous. Unfortunately, these p-e journals are uncritically mixed with pure e-journals and e-p-journals by analysts such as Okerson [42] and Tenopir and King [46]. Okerson, for example, estimated that there were over 8,000 e-journals at the turn of the century. This is a wild over-estimate, if by e-journal one has the cultural model of "free to authors, free to readers." In 2001, Walt Crawford [7] examined the status of 104 scholarly pure e-journals that were founded before 1995, and learned that only 49 of these 104 e-journals were still publishing and were free to readers.

There is a huge difference between a few dozen viable pure e-journals and an estimate of 8,000 . Why does this difference matter? It matters because if there were 8,000 viable pure e-journals that fit the typical cultural model, then these journals would seem to be easy to develop and sustain. In contrast, Crawford's estimate of a less than $50 \%$ survival rate suggests that developing a new pure e-journal is a complex undertaking that requires some significant socio-technical analysis about how to mobilize appropriate authors, readers, editors, and to keep the project viable [24][25].

As a last example, I will contrast a conventional cultural model of IT applications/services with a socio-technical model that is based on an intriguing body of empirical research. The conventional cultural model of IT applications focus almost solely on their information processing characteristics and costs and posit specific effects due to those features. Mathematician Andrew Odlyzko [41], for example, predicted that the size of 
academic publishers and libraries would shrink substantially because the affordable costs of computer hardware enabled scholars to organize and edit their own electronic journals. While Odlyzko noted that the pace of change would be influenced "primarily by sociological factors," the information processing costs for electronic journals made a transition to them inevitable. In contrast Kling and Callahan [25] observe that the vast majority of the 8,000 electronic journals counted by Okerson are in fact hybrid editions that are sold in both paper and electronic forms. Information processing analyses like Odlyzko's are to be expected when information processing features dominate in an analysis. This cultural model of IT applications is common in computer science where the theoetical landscape is officially limited to computational formulations (for example, NRC [38], and Bajcsy and Reynolds [2]).

An alternative conception of IT applications views them as "sociotechnical networks," that is, ensembles that include many different elements, such as IT hardware, software, legal contracts and people in relationship to each other and other ensemble elements. As a socio-technical network, a electronic journal is not merely a set of electronic documents, but a set of electronic documents that have gone through some kind of social editorial process, that are stored in structured electronic spaces where only some people have the authority to place them or to modify them. Further, the journal's status depends in part, on other networked relationships, such as the prestige of its editorial board and institutions or scholarly societies that sponsor it [24]. The articles are likely to be copyrighted, and perhaps stored in a technical format that increases the costs of a reader copying them (ie., say postscript rather than HTML). A functioning electronic journal is an intertwined network of social and technical elements that are inseparable in practice. This socio-technical conception is rather strange to computationally oriented computer scientists.

\subsection{Institutional Circuitry}

But how would IT students or IT professionals learn about a sociotechnical network conception of of IT applications? My answer hinges on another concept, that of "institutional circuitry." Agre [1] abstractly characterized institutional circuitry as "the forms and pathways that specific social formations maintain for the movement of their own categories of communicative practice." He went on to amplify this conception in these terms: 
"The institutional circuitry of academia ... includes the production and distribution of scholarly books and journals, but it also includes the circulation of draft papers, the ritualized explanation of one's research to others at conferences, the accelerating chatter of electronic mail, and the promotion of keywords." (from Agre, [1])

In a similar way, we observe that the institutional circuitry of mainstream IT Discourse for students is based on textbooks and other teaching materials, as well as mass media, including films and magazines. For IT professionals, institutional circuitry of mainstream IT Discourse is more complex, and includes trade newspapers (ie., Infoweek, Computerworld), magazines (ie., Datamation), books (as sold by the ACM, the IEEE, or in mass market bookstores), conferences (ie., Comdex, SIGCHI), and specialty seminars.

In contrast, we also identify an institutional circuitry of scholarly social informatics discourse. In the U.S., this includes distribution channels such as university libraries (for journals such as The Information Society and Information Technology \& People), research conferences, and universitybased seminars. These serve as forum for the construction and interpretation of scholarly critique and debate about IT applications in practice, and as channels through which empirically anchored conceptualizations about IT and social life circulate.

These characterizations are brief sketches. Each set of institutional circuits is much more elaborate and complex. The messages carried within these institutional circuits are shaped and reformed to match the nature of the circuit. For example, the institutional circuitry of mainstream professional IT discourse found in airplanes and frequent flyer clubs where traveling professionals can readily find popular business magazines (but not scholarly journals) often focus on short, attention-grabbing topics that a particular pith to the traveling professional. In contrast, messages carried within the institutional circuitry of scholarly social informatics discourse funneled through the assigned readings for some specialized courses and the informal circulation of pre-published manuscripts among scholars follows the prescriptive traditions of appropriateness and style for academic reporting expected in that circuit.

These circuits and the ideas that flow through them overlap at some points. It would take a different study to map out these institutional circuits in detail, as well as their relative influence for different constituencies. 


\section{DISCOURSES ABOUT IT APPLICATIONS AND SOCIAL LIFE}

There are several different Discourses about IT and social life in North America. Different institutional circuits dominate in channeling these Discourses between participants. One of Discourses is technocentric, and like Odlyzko's analysis that I described earlier, emphasizes the significance of new technological developments as a driver of social change. Another Discourse about IT and social life is managerialist, and views IT applications and services from the perspective of (upper) managers. Much of the literature about reengineering organizations is written from this perspective.

Yet a different Discourse, that of social informatics, is based on systematic research about IT applications and social life. "Social informatics refers to the interdisciplinary study of the design, uses and consequences of IT that takes into account their interaction with institutional and cultural contexts. Social informatics research comprises normative, analytical, and critical orientations, although these approaches may be combined in any specific study" [24].

The critical orientation refers to examining ITs from perspectives that do not automatically and uncritically accept the goals and beliefs of the groups that commission, design, or implement specific IT applications. This critical orientation differs from Frankfurt School "critical theory." Also, it is not "merely critical" in the sense of finding faults. It is evidence-based discourse that contrasts with a flattened discourse that simply promotes new forms of IT and criticizes the use of 'old technologies."

The critical orientation is possibly the most novel [1]. It encourages information professionals and researchers to examine ITs from multiple perspectives (such as those of the various people who use them in different contexts, as well as those of the people who pay for, design, implement or maintain them), and to examine possible failure modes and service losses, as well as ideal or routine IT operations.

This critical orientation refers to systematic examinations of assumptions about the relationships of IT application configurations and social life and the evidence for various claims about IT applications and social life. It can examine the ways that these relationships may vary with cultural and institutional contexts. It can examine ends as well as means to achieve them.

IFIP has played some role in developing a critical IT Discourse such as this. TC-9's "Computers and Human Choice" conferences help to develop such as critical Discourse. TC-9 has also created one textbook [4] and is currently creating a textbook that is explicitly named: Critical Perspectives on the Information Society. Other IFIP working groups also support developing a critical Discourse about IT and social life. 
For example, WG 8.2 on "information systems in organizations," lists as one of its five official aims: "To nurture a critical discourse about the role which IT plays in the lives of people as individuals and as members of complex social institutions such as government, community, business, professional societies and other forms of social associations" (see http://www.ifipwg82.org/noframes.php3).

There is a growing body of knowledge about the relationships between IT applications and social life which should form one part of the education of IT professionals $[4,19,21,22,23,24,27,28,30,33,34,47]$. It includes conceptions of IT applications as the kind of socio-technical networks that I discussed above. In addition, it includes an understanding that IT applications alone are not sufficient to substantially alter social or organizational behavior. Markus and Benjamin [33] refer to the stance that IT applications alone are sufficient to alter (and improve) social or organizational behavior as a "magic bullet theory." Markus and Benjamin believe that many IT professionals hold a magic bullet theory of IT and organizational change, and further that their beliefs position them as heroes whose programming or configuring an IT application is the basis for organizational (or social) value to come from it. In practice, social informatics researchers have found that other social practices, such as organizational reward systems, may have to be changed to create the conditions for an IT application to be of value [24].

Some North American computer scientists understand this idea as well. Writing about the use of the Internet to enrich high school education, Soloway and Wallance [45] note that simply providing Internet access in classrooms is far from sufficient to improve education. Their research lead them to conclude that the effective educational use of the Internet to enrich students' inquiry required both pedagogical reforms and teaching students how to effectively use search engines. While they don't use Markus and Benjamin's "magic bullet" nomenclature, in effect they are saying that the Internet access in U.S. classrooms is not a magic bullet to improve education. In fact, they argue that ineffective Internet use is a genuine waste of students' time.

\section{SOCIAL INFORMATICS DISCOURSE IN THE EDUCATION OF IT PROFESSIONALS}

There are several major institutional loci for the systematic education of IT professionals in the U.S., including academic computer science departments, information systems departments in business schools, and 
instructional technology departments in schools of education. In addition, there are two new kinds of related formations: information schools and "IT schools."

The information schools are based on an expansion of the scope and mission of what were schools of librarianship in the 1980s. Some, such as one at the University of Michigan changed its name from the School of Library and Information Studies to the School of Information. The University of Washington renamed its Graduate School of Library and Information Science as The Information School. Indiana University did not change the name of its School of Library and Information Science, but created a new Master's degree in information science and renamed it's Ph.D. in "library and information science" as a Ph.D in information science. At least a dozen other universities have significantly restructured their research and instructional programs that emphasized librarianship to include the education of IT professionals.

The new "IT schools" [9] come in two flavors. One group of IT schools are expanded from computer science departments, and include the School of Computer Science at Carnegie Mellon University and the College of Computing at the Georgia Institute of Technology. The other flavor is the creation of completely new schools, such as the School of Information Science and Technology at Pennsylvania State University and the School of Informatics at Indiana University. These new academic formations were often stimulated by a concern that computer science departments were neither sufficiently broad or flexible to effectively educate a wide range of IT professionals.

Today, of these different formations, computer science departments and information systems departments currently formally educate the largest number of IT professionals. Official statistics indicate that there were approximately two million IT professionals in the U.S. in 1998 [11: 34-37]. We don't know how many of these IT professionals were formally educated in an academic IT program, and how many entered occupations such as programming, systems analysis or website design from another field (such as mathematics, management or the arts).

\subsection{Computer Science}

Freeman and Aspray report that approximately 25,000 students a year were awarded B.S. degrees in computer science and 10,000 were awarded M.S. degrees. In the course of a decade, this would lead to somewhere between 250,000-350,000 students earning computer science degrees in the U.S. 
To what extent would many or most of these several hundred thousand computer science graduate be systematically exposed to a critical social informatics Discourse about IT and social life? My suspicion is that relatively few have this kind of exposure. Some computer science offer a "computers and society" course, but few departments require it for their graduates. Further, the amount of critical social informatics research that is coming from computer science departments seems to be actually less than in the late 1970s! In the late 1970s, critical social informatics discourse was advanced by computer scientists in the U.S. such as Joe Weizenbaum [48], Abbe Mowshowitz[37], and me[21], among others. One might have expected this line of inquiry to strengthen in computer science departments as the range of IT applications touches reaches much more widely through North America. While social informatics research is increasing it its amount, sophistication, and the range of topics treated, less of the writing comes from faculty of computer science departments in the U.S. Some of the social informatics researchers who held primary appointments in computer science in the 1980s have moved to information schools in the 1990s.

It is helpful to ask why there has been a substantial decline in the amount of critical social informatics research conducted in computer science departments. Of course, all answers to such a question have a speculative dimension. However, I believe that there is a "critical chill" in the culture of many academic computer science departments. I should be clear that the Discourses of IT applications and social life are varied in North American computer science. The ACM's journal for all members, Communications of the $A C M$, includes some critical social informatics discourses But the majority of these are written by scholars from other fields, such as political science, information systems, and information science. The ACM also sponsors special interest groups (SIGs) in human-computer interaction (SIGCHI), computer supported cooperative work (SIGGROUP), information systems (SIGMIS), and issues of the IT professions (SIGCPR) whose conferences include critical social informatics research. However, this research is rarely conducted by faculty who are based in academic computer science departments. Further, the ACM no longer supports research journals which would be good outlets for social informatics research. Since the early 1990 s, Communications of the $A C M$ has shifted from a journal that published original research studies to a magazine that publishes articles based on research, but written for the ACM's large number of professional members. The ACM's professional membership is probably better served by the current form of Communications of the ACM. But the ACM did not open up other journals for social informatics research. In fact, the most likely candidate journal, Transactions on Information Systems, narrowed its emphasis to information retreival in the mid-1990s. 
The Computer Science and Telecommunications Board of the National Research Council sometimes publishes critical social informatics research[39]. However, the panels that produce these reports depend heavily upon the expertise of scholars in other fields (such as history, political science, information systems, and law).

I speculate that this "critical chill" is a byproduct of identifying mathematics as the only legitimate kind of theoretical orientation in computer science. When the first computer science were founded in the U.S. in the 1960s, the field was not well understood by senior scholars in other disciplines, such as chemistry. Computer science was seen by many academics as "programming" -- and certainly programming was featured in many computer science courses. The extent to which computer scientists were theorizing about different kinds of systems architectures (say for operating systems or artificial intelligence applications) was not part of the rest of the world's cultural model of computer science. By using mathematics as the reference point for "all theory," computer scientists were able to raise their status with colleagues in other disciplines. I see several markers.

1. Explanation of theoretical computer science to others: For example, when the National Resaerch Council[38] issued a report to make the case for expanded computer science research funding, the chapter devoted to "theoretical research" emphasizes mathematical ideas, like number theory, rather than other kinds of theoretical advance such as semantic nets representations in artificial intelligence, object-oriented programming, systems development with rapid prototypoing, or participatory design as a way of improving IT applications. The report, in fact notes:

"Although most of these ideas have a basis in mathematics, they have become so firmly fixed in the instincts of computer scientists and engineers that they are likely to be used as naturally as a cashier uses arithmetic, with little attention to the origins of the process. In this way, theory pervades the daily practice of computer science and lends legitimacy to the very identity of the field."

2. Language use in computer science: The label "theoretical computer science" is equivalent to "mathematical computer science." The label "foundations of computer science" identifies a conference and a journal that are devoted to mathematical computer science. A logician who holds an academic appointment in a philosophy department can identified as working in a major area of philosophy, one that is parallel in status to epistemology, metaphysics, aesthetics and ethics. That philosopher would not claim to be studying the "foundations of philosophy," in the sense that formal logic coul provide an adequate basis for ethics, aesthetics, etc. However, the same logician were appointed in a computer science department, s/he could claim to work in the "foundations of computer science" without any controversy. 
In May 2002, my Google search for "logical foundations of computer science" produced about 900 hits, while a Google search for "social foundations of computer science" produced zero.

3. Theoretical discussions within computer science: For example, Bajcsy and Reynolds'[2] recent article "Computer Science: The Science of and about Information and Computation" advances an exclusively computational view of information as a computer science approach. Even though the article refers to the "contextual nature of information," it doesn't discuss how important contextual elements can be social and cultural or how the demand for Internet services has grown because of the ways that they can expand the range of human communication.

What is the problem with the theoretical hegemony of logic and mathematics in U.S. computer science? How does it foster a critical chill? Part of the answer comes from Harris and Henderson [15] who observe that the mathematical orientation of computer science leads to an emphasis upon explanations that must be coherent and consistent. The concept of "rigorous analysis" in computer science is based on a cultural model that identifies with a formalism, coherence and consistency. Concepts like the sociotechnical network, described above, do not seem particularly rigorous and therefore not "high quality" in computer science. I do not claim that mathematical computer scientists have a distinctive hostility to a critical Discourse about IT and social life. Rather, the numerous small ways that academic cultures are created and reproduced -- through the organization of curricula, criteria for selecting graduate students, reviewing faculty research -- all tilt in ways that makes critical social informatics research difficult to develop and sustain with computer science departments. The spillover into education is that faculty who do not appreciate critical social informatics research are much less likely to create parts of their curricula to enable their students to learn about it in a deep and sustained way. As a consequence, only a small fraction of the approximately 35,000 B.S. and M.S. students graduating annually in computer science are likely be exposed to a serious critical Discourse about IT and social change.

\subsection{Information Schools and IT Schools}

In 2002, the transformed information schools and new IT schools provide a more fertile ground or critical Discourse about IT and social life. Some of the information schools, in particular, were more heterodox in their disciplinary variety. Even when they were exclusively schools for library science, some of their faculty had been educated in the social sciences and humanities. Consequently, social informatics is not the paradigmatic stretch for them that it can be in most computer science departments. In addition, 
there are social informatics faculty in the information schools at Indiana University, the University of Washington, the University of Illinois, Rutgers University, the University of California at Berkeley, the University of California at Los Angeles, and the University of Illinois. The number of such appointments has been growing and represents a kind of expertise in the critical Discourse about IT and social life that reaches more deeply into these schools' curricula.

The formation of the newer IT schools is less settled. Much will depend upon how heterogeneous a faculty they appoint or engage in a serious curricular manner. If they characterize their orientation as "applied computer science," they risk carrying the cultural models of "rigor is logic and mathematics" that have chilled social informatics Discourse in most computer science departments. Some "IT school" faculties, such as the School of Computer Science at Carnegie Mellon University, have specifically departmentalized to enable greater paradigmatic heterogeneity. Others, like the School of Informatics at Indiana University has integrated social informatics into its undergraduate curriculum. The School of Information Science and Technology at Pennsylvania State University has gone farther, by explicitly including social informatics expertise -- framed as a "social impact perspective" -- into a set of "overarching competencies" that they want to develop in their students.

\section{CONCLUSIONS}

I have portrayed a rather bleak view of the likelihood of U.S. computer science departments in effectively educating their students who will become IT professionals (rather than, say researchers) to understand and be able to learn from the developing critical Discourses about IT and social life. Traditionally, IFIP's TC-9 has been oriented towards computer science more than any other discipline. In the U.S., there are new kinds of academic programs for IT professionals that may provide a more effective liaison with TC-9: information schools and the IT schools. While there is substantial heterogeneity among these new programs, they seem to provide the educational spaces that are most likely to educate and bring future IT professionals to competantly participate in critical Discourses about IT applications and social change. 


\section{REFERENCES}

1. Agre, Philip E. and Schuler, Douglas. eds. 1997. Reinventing Technology, Rediscovering Community Critical Studies in Computing as a Social Practice. Greenwich, CT: Ablex Publishing.

2. Bajcsy, Ruzena and Reynolds, Craig. 2002. Computer Science: The Science of and about Information and Computation. Communications of the ACM, 45(3)(March):94-98.

3. Behar, Michael. 2002. The New Mobile Infantry: Battle-ready robots are rolling out of the research lab and into harm's way. Wired. 10.05 - May 2002 http://www.wired.com/wired/archive/10.05/robots_pr.html

4. Berleur, Jacques, Clement, Andrew, Sizer, Richard and Whitehouse, Diane. eds. 1988. The Information Society: Evolving Landscapes. New York: Captus University Publications and Springer-Verlag.

5. Brooks, Frederick. 1975. The Mythical Man-Month: Essays on Software Engineering. MA: Addison-Wesley.

6. Carroll, John M. and Rosson, MaryBeth. 2001. Better home shopping or new democracy?: evaluating community network outcomes. In Proceedings of the SIGCHI conference on Human factors in computing systems (pp. 372 - 379). New York: ACM Press.

7. Crawford, Walt. 2002. Free electronic refereed journals: Getting past the arc of enthusiasm. Learned Publishing, 15:117-123.

8. Davidson, Ann, Schofield, Janet, and Stocks, Janet. 2001. Professional Cultures and Collaborative Efforts: A Case Study of Technologists and Educators Working for Change. The Information Society, 17(1): 21-32.

9. Denning, Peter J. 2001. The IT schools movement. CACM 44(8): 19-22.

10. Foley, Alan. 2000. Beyond Critical Consumption: Analyzing a Web Site using Mode of Address, Discourse Analysis, and Symptomatic Reading. Paper presented at the 2000 Association for Educational Communications and Technology (AECT). International Conference. Denver, Colorado.

11. Freeman, Peter and Aspray, William 1999. The Supply for Information Technology Workers in the United States. Washington, DC: The Computing Research Associatn

12. Fountain, Jane E. 2001. Building the Virtual State: Information Technology and Institutional Change. Brookings Institution Press.

13. Gee, James Paul. 1999. An Introduction to Discourse Analysis: Theory and Method. London: Routledge.

14. Hara, Noriko and Rob Kling. (in press). Students' Difficulties in a Web-Based Distance Education Course: An Ethnographic Study. In Digital Academe: New Media and Institutions in Higher Education and Learning .eds. William H. Dutton and Brian D. Loader. London: Taylor \& Francis/Routledge.

15. Harris, Jed, and Henderson, Austin. 1999. A Better Mythology for System Design. In Proceedings Human Factors in Computing Systems, CHI99 (pp. 88-95). New York: ACM Press. 
16. Heracleous, Loizos and Barrett, Michael. 2001. Organizational change as discourse: Communicative actions and deep structures in the context of information technology implementation. Academy of Management Journal, 44(4): 755-778.

17. lacono, Suzanne and Kling, Rob. 2001. Computerization Movements: The Rise of the Internet and Distant Forms of Work. In Information Technology and Organizational Transformation: History, Rhetoric, and Practice, eds. JoAnne Yates and John Van Maanen. pp. 93-136. Thousand Oaks, CA: Sage publications.

18. Joy, Bill. 2000. Why the Future Doesn't Need Us. Wired. 8.04 http://www.wired.com/wired/archive/8.04/joy.html

19. Kiesler, Sara. ed. 1997. The Culture of the Internet. Mahwah, NJ: Lawrence Erlbaum Associates.

20. Kling, Rob. 1980a. Social Issues and Impacts of Computing: From Arena to Discipline Proc. Second Conference on Computers and Human Choice (Vienna, June 1979) Amsterdam: North Holland Publishing Co.

21. Kling, Rob. 1980b. Social Analyses of Computing: Theoretical Perspectives in Recent Empirical Research. Computing Surveys, 12(1)(March 1980):61-110.

22. Kling, Rob. 1993. Organizational Analysis in Computer Science. The Information Society. 9(2): 71-87.

23. Kling, Rob. 1996. Computerization and Controversy: Value Conflicts and Social Choices. (2nd ed.). San Diego: Academic Press.

24. Kling, Rob. 2000. Learning about Information Technologies and Social Change: The Contribution of Social Informatics. The Information Society 16(3):217-232.

25. Kling, Rob and Callahan, Ewa.(in press). Research Articles in Scholarly Electronic Communication. In Annual Review of Information Science and Technology (ARIST), -(volume 37) . eds. Blaise Cronin and Debora Shaw. Medford, NJ: Information Today, Inc.

26. Kling, Rob and Courtright, Christina. (forthcoming) Group Behavior and Learning in Electronic Forums: A Socio-technical Approach. In Building Online Communities in the Service of Learning Editors. eds. Sasha Barab, Rob Kling, and James Gray. Cambridge: Cambridge University Press, UK.

27. Kling, Rob, Crawford, Holly, Rosenbaum, Howard, Sawyer, Steve and Weisband, Suzanne. 2000. Learning from Organizational and Social Informatics: Information and Communication Technologies in Human Contexts. Center for Social informatics. (http://www.slis.indiana.edu/CSI). Indiana University, Bloomington.

28. Kling, Rob \& Lamb, Roberta. 2000. IT and Organizational Change in Digital Economies: A Socio-Technical Approach. In Understanding the Digital Economy -Data, Tools and Research .eds. Brian Kahin and Erik Brynjolfsson. MA: The MIT Press.

29. Klinger, Shula. 2000. Are they talking yet? Online discourse as political action. Paper presented at the Participatory Design Conference, CUNY, New York. (November 2000).

30. Kubicek, Herbert, Dutton, William and Williams, Robin. eds. 1997. The Social 
Shaping of Information Highways: European and American Roads to the Information Society. Frankfurt am Main and New York: Campus Verlag and St. Martin's Press.

31. Kurzweil, Ray. 1999. Age of Spiritual Machines. Penguin books.

32. Leveson, Nancy. 1995. Safeware: System Safety and Computers. MA: AddisonWesley.

33. Markus, M. Lynne, and Benjamin, Robert I. 1987.The magic bullet theory in ITenabled transformation. Sloan Management Review. Cambridge (Winter) 38(2):5568.

34. Markus, M. Lynne and Keil, Mark. 1994. If We Build It, They Will Come: Designing Information Systems That People Want to Use. Sloan Management Review. 35(4)(Summer): 11-25.

35. Marx, Leo. (1987). Does improved technology mean progress? Technology Review, 90(1): 33-41, 71 .

36. Mitev, Nathalie. 2000. Toward social constructivist understandings of IS success and failure: introducing a new computerized reservation system. In Proceedings of the 21st international conference on Information systems (pp.84-93). Brisbane, Queensland, Australia.Association for Information Systems Atlanta, GA, USA.

37. Mowshowitz, Abbe. 1976. The Conquest of Will. MA: Addison-Wesley.

38. National Research Council, Computer Science and Telecommunications Board (CSTB). 1999. Funding a Revolution: Government Support for Computing Research. Washington, DC: National Academy Press.

39. National Research Council (US), Committee to Study Global Networks and Local Values. 2001. Global networks and local values: a comparative look at Germany and the United States. Washington, DC: National Academy Press.

40. Neumann, Peter G. 1995. Computer-Related Risks. MA: Addison-Wesley.

41. Odlyzko, Andrew. 1995. Tragic loss or good riddance: The impending demise of traditional scholarly journals. International Journal of Human-Computer Studies, 42:71-122. (http://www.dtc.umn.edu/ odlyzko/doc/eworld.html)

42. Okerson, Ann. 2000. Are we there yet? Online e-resources ten years after. Library Trends, 48:671-694.

43. Orlikowski, Wanda J. 1993. Learning from Notes: organizational issues in groupware implementation. The Information Society 9(3): 237-250.

44. Petroski, Henry. 1992. To Engineer Is Human: The Role of Failure in Successful Design. New York: Random House.

45. Soloway, Elliot and Wallace, Raven. 1997. Does the Internet Support Student Inquiry? Don't Ask. $C A C M$ 40(5): 11-16.

46. Tenopir, Carol and King, Don.W. 2000. Towards electronic journals: Realities for scientists, librarians and publishers. Washington, DC: Special Libraries Assoc.

47. Walsham, Geoff. 2001. Making a World of Difference: IT in a Global Context. NY: John Wiley.

48. Weizenbaum, Joseph. 1976. Computer Power and Human Reason. San Francisco, CA: W.H. Freeman. 